\title{
Thermomechanical Behavior of Steels in Tension Studied with Synchronized Full-Field Deformation and Temperature Measurements
}

\author{
G.C. Soares ${ }^{1}$ (D) $\cdot$ N.I. Vázquez-Fernández ${ }^{1}$ (D) $\cdot$ M. Hokka ${ }^{1}$ (D) \\ Received: 26 June 2020 / Accepted: 28 December 2020 / Published online: 19 February 2021 \\ (C) The Author(s) 2021
}

\begin{abstract}
Despite tensile testing being commonly used for investigating the mechanical behavior of materials, the occurrence of heterogeneous strain and increasing temperature at high strain rates make the experiment much more complex. This work presents a method integrating synchronous full-field stereo Digital Image Correlation (DIC) and Infrared Thermography (IRT). This method enabled high resolution investigations of the development of local temperatures and strains of the specimen during tensile loading of four steels at strain rates ranging from $2.5 \cdot 10^{-4}$ to $900 \mathrm{~s}^{-1}$. The tests were monitored by a stereo setup of optical cameras and an infrared camera. Data acquisition was synchronized, and a pinhole camera model was used to translate the images from all cameras to the same three-dimensional space. The displacement vector fields from DIC were subtracted from the IRT images to represent the temperature maps in a Lagrangian coordinate system. The overall thermomechanical response of the materials was shown as 3D waterfall plots, which represent localized strain and temperature as a function of position and engineering strain. The results show that temperature increased homogeneously during uniform deformation at higher strain rates $\left(10^{-2}-900 \mathrm{~s}^{-1}\right)$ and increased markedly with the onset of necking on the region of localized strain. At these strain rates, the localized increase of strain and temperature during necking were observed at the same global engineering strain and position, evidencing the spatial and temporal synchronization. The described method was used to accurately investigate the evolution of localized strain and temperature in both low and high strain rate regime.
\end{abstract}

Keywords Stereo digital image correlation - Infrared thermography · Full-field measurements · High strain rate . Thermomechanical behavior $\cdot$ Tensile testing $\cdot$ Advanced high strength steels

\section{Introduction}

Tensile testing is widely used for investigating the mechanical behavior of materials. It is effortless to perform and promptly provides material properties such as the elastic modulus, yield

G.C. Soares

guilherme.correasoares@tuni.fi

N.I. Vázquez-Fernández

naiara.vazquez@tuni.fi

M. Hokka

mikko.hokka@tuni.fi

1 Impact - Multiscale Mechanics Testing Group, Engineering Materials Science, Faculty of Engineering and Natural Sciences, Tampere University (TAU), POB 589, FI-33014 Tampere, Finland strength, tensile strength and ductility. An extensometer is generally used to measure total strain in the sample gauge length in these tests [1]. However, strain localization occurs in phenomena such as necking [2], Lüders bands [3], Portevin-Le Chatelier bands [4], and adiabatic shear bands [5]. Extensometers are not able to properly measure nonhomogeneous strains during tensile tests, and thus, are not ideal for investigating complex material behavior. Furthermore, unless performed at very low strain rates, the temperature of the tested sample is not constant and increases with deformation. Measuring sample temperature during testing is not a trivial task, as thermocouple do not react to temperature changes fast enough in high-speed testing and pyrometers only provide single average temperature values. The analysis of material behavior is made more complex by the combination of both heterogeneous strain and continuously changing temperature of the material during testing. These matters can be addressed 
using full-field techniques to monitor both strain and temperature across the whole sample during mechanical testing.

Inhomogeneous strains during mechanical testing have been measured using DIC in previous research. Gilat et al. [6] measured the local deformations in compression and tensile specimens tested in Split Hopkinson Bar experiments using 3D DIC, and presented the results as waterfall plots where the local strain is presented as a function of time and spatial coordinates of the specimen. Koerber et al. [7] monitored the heterogeneous strains during the failure of uniaxial polymer composites during dynamic tests. They used DIC to investigate compression tests of samples with different fiber orientation angle and obtained its transverse compression and shear properties. Peirs et al. [8] used DIC to determine the stress-strain behavior of metals at large strains from high strain rate tensile and shear tests in Ti6Al4V. They showed that strain localizes under both tensile and shear dynamic loading, and that the combination of DIC and finite element modelling can be used for studying material behavior. Zhang \& Zhao [9] measured the full-field strain development in fine-grained marble tested under a dynamic compressive load. They demonstrated that full-field strain data from DIC is as reliable as strain gages and were able to observe the strain evolution that accompanied crack propagation in a rock sample. Moilanen et al. [10] investigated wood samples in compression, and were able to observe the heterogeneous evolution of local strains in the different layers in their samples. Johsen et al. [11] used the full-field images to characterize the inhomogeneous local strains evolution in polymer tension specimens up to large strains. Verleysen \& Peirs [12] used DIC to investigate the strain localization in in-plane shear, in-plane tensile and plane strain sheet Ti6Al4V samples during static and dynamic experiments. In their work, strain localizations were fundamental in the fracture process, and precise measurement of the localized strain evolution was important for their finite element model validation. Most of the recent literature that reports use of DIC to monitor full-field strain development present the results either as averaged strain values $[7,9,11$, 13] and/or as strain maps, which were often overlaid on top of the optical photographs used in the analysis [7-10]. Although the full-field strain maps are useful to present the strain localization, a great number of images are required to represent the strain evolution as a function of time even for a single experiment. Furthermore, it is not an easy task to obtain useful information by comparing a multitude of strain maps, which can sometimes have different color scales due to the different minimum and maximum strain values in every moment in time.

There have also been various approaches to characterizing the temperature evolution in materials during a high rate loading, which extend from using thermocouples, infrared detectors, and infrared cameras. Fuller et al. [14] employed a combination of thermocouple junctions and a temperature sensitive liquid to investigate the temperature of a crack tip in glassy polymers. Rittel [15-17] used small thermocouples embedded in polymer samples to investigate the temperature evolution under dynamic loading. The thermocouples, unfortunately, have a longer response time (10-20 $\mu \mathrm{s}$ [15]) and their applicability in high rate loading remains questionable. Furthermore, thermocouples only output a voltage value and are not appropriate for characterizing spatial temperature distributions or temperature localizations. They cannot identify shear bands or other localizations, as they only measure the average temperature of an area. Fuller et al. [14] acknowledge in their work that thermocouples can only provide a measure of total heat in a process and that better spatial resolution is necessary to obtain accurate values of the temperatures in phenomena with localized strain. Marchand \& Duffy [5] used an array of twelve InSb infrared detectors to investigate the formation of adiabatic shear bands in steel. Zhou et al. [18] employed a similar but improved system with sixteen detectors that were aligned either parallelly or perpendicularly to shear band propagation. With such arrangement, the scientists were able to use a waterfall plots to represent the increase in temperature for different points in space as a function of time. Zehnder \& Rosakis [19] used a similar vertical array of eight $\mathrm{InSb}$ infrared detectors to measure the temperature distribution around a horizontally propagating crack in steel. This array allowed them to obtain contour maps of the temperature increase in the region near the crack tip. Although such systems with InSb detectors can have a very low response time (0.5 $\mu \mathrm{s}$ [18]) and high acquisition rate (up to $300 \mathrm{MHz}$ [19]), they can struggle with low signal-to-noise ratio. The application of an array of infrared detectors was a development which allowed the acquisition of rudimentary temperature maps of dynamic events. The InSb high-speed thermal signal recording systems are still currently used in research that does not require full-field temperature measurements, as for example, Zhang et al. [20] used it to investigate the dynamic thermomechanical behavior of titanium alloys. The development of infrared cameras opened the possibility for temperature maps with higher spatial and temporal resolution, which could be used to investigate dynamic events. Noble \& Harding [21] used a thermal scanning camera for investigating the temperatures in an iron tensile sample deformed at high strain rate. The authors were able to monitor the dynamic event by using the fact that the time interval for the camera to scan each pixel took approximately $2 \mu \mathrm{s}$. The aim of the authors in this study was to measure the maximum increase in temperature, and while the technique allowed them to get this 
information, they were not yet able to get full-field temperature maps of their tests. Gilat et al. [22] and Seidt et al. [23] used high-speed infrared cameras to investigate the temperature evolution in high strain rate tensile tests in Ti6Al4V and stainless steel. These works displayed full-field temperature maps of tensile tests with strain rates up to $3000 \mathrm{~s}^{-1}$, and the data was mostly presented as $2 \mathrm{D}$ waterfall plots of temperature as a function of time and position along the gauge length. Johnston et al. [24] used a high performance thermal camera to investigate the increase in temperature on braided composites subject to ballistic impact. The temperature maps allowed the visualization of localized temperature increase in the specimens, which were related to their local failure mode and heat generating mechanisms.

Nevertheless, there are only a few published studies where the full-field deformation and temperature of specimens have been obtained in high rate loading. The combination of Digital Image Correlation (DIC) and Infrared Thermography (IRT) can provide robust framework for investigating the thermomechanical behavior of materials. DIC and IRT are both full-field and non-contact characterization techniques and do not depend on the analyzed material or the involved scale. Hence, these techniques are versatile and appropriate for many applications in which there is importance in characterizing the deformation and the temperature development in solids [25]. However, these techniques provide a massive amount of data, which can lead to research being overloaded by data and averaging their full-field results. To fully take advantage of these techniques, it is important to represent and analyze them in the most optimal manner. Recent efforts have shown that the integration of full-field IRT and DIC is suitable for analyzing the thermomechanical behavior of materials under high strain rate conditions [22, 23, 26]. Synchronized strain and temperature data can be used to analyze a material local energy balance during deformation and determine the fraction of plastic work converted into heat. With such analysis, it is possible to obtain information on the active deformation mechanisms and the microstructural evolution, as well as obtain data for more accurate plasticity models $[22,27]$. The combination of these techniques is very powerful and can be applied to the investigation of many intricate phenomena such as Lüders band formation and propagation, phase transformation, and pseudoelasticity in shapememory alloys, and strain hardening/softening [6].

Although other studies have already employed full-field 2D DIC and IRT to analyze the thermomechanical behavior of materials, data acquisition synchronization between the two systems has not been optimal in the tests that required the highest frame rates. Seidt el al. [23] used a wave generator to synchronize data acquisition during their tests at low and medium strain rates. However, in the high strain rate tests the high-speed Photron camera was set to preset frequency that was a multiple of the acquisition frequency being sent to the IR camera and had only the onset of recording being done by the wave generator. Gilat et al. [22] did not specify how the synchronization between 2D DIC and IRT was performed. Smith et al. [26] performed a thermomechanical analysis of the behavior of a Ti-6Al-4 V at high strain rates using DIC and IRT, but had different frequencies for the high-speed camera and the IR camera during the high-speed tests and used interpolation to perform their analyses.

The novelty of this work lies in the use of full-field stereo DIC and IRT high-speed measurements being externally synchronized with the help of a function generator and an analog gate. This synchronization allowed the acquired data to be accurately translated to the same Lagrangian coordinate system and utilized for the thermomechanical analysis of four different steels with a distinct combination of microplasticity mechanisms. The use of stereo DIC, rather than 2D DIC, allowed dimensional displacement measurements to be free of any out-of-plane bias and thus improved the localized strain measurement and the translation of IRT data to the Lagrangian coordinate system. Furthermore, this paper demonstrates the use of 3D waterfall plots instead of the stress-strain curves as a mean of analyzing thermomechanical behavior of materials. These plots can effectively describe the strain and temperature evolution in a tensile test and could easily be used for verification of material models. This work presents a novel implementation of synchronized full-field stereo DIC and IRT to analyze the thermomechanical response of four advanced steels to tensile deformation at wide range of strain rates.

\section{Experimental Methods}

\section{Materials}

The investigated materials in this work were a metastable austenitic stainless steel (AISI301), a stable austenitic stainless steel (AISI316), a low alloy transformation induced plasticity

Table 1 Dimensions of the dog-bone tensile samples ( $\mathrm{mm}$ )

\begin{tabular}{lllllll}
\hline Steel & G & W & T & B & C & L \\
\hline AISI301 & 8 & 4 & 2 & 25 & 22 & 62.5 \\
AISI316 & 8 & 4 & 2 & 25 & 22 & 62.5 \\
TRIP700 & 6 & 4 & 1.7 & 30 & 22 & 68 \\
TWIP & 6 & 4 & 2 & 30 & 20 & 68 \\
\hline
\end{tabular}




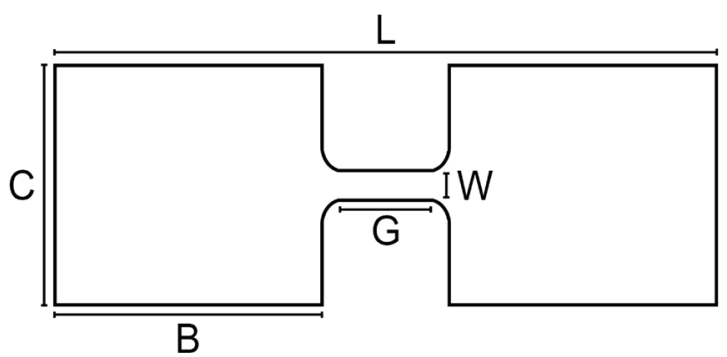

Fig. 1 Specimen geometry used for the tensile tests

steel (TRIP700), and a twinning induced plasticity steel (TWIP). The TWIP steel was not a standard steel, but was prepared, cast and hot rolled as specified in refs. [28-30]. These four advanced steels were selected on the grounds of their distinct combination of deformation mechanisms and straightforward availability. These steels exhibit microplasticity mechanisms such as mechanical twinning, phase transformations, and dislocation glide. Dog-bone tensile samples machined from thin cold or hot rolled sheets were used in this investigation. The specimen geometry and dimensions for each steel are shown in Table 1 and Fig. 1. Permanent marker was used to create a random black speckle pattern for the DIC on the gauge section of one side of the specimen leaving the opposite side of the specimen clean for the IRT imaging.

\section{Experimental Setup}

Tensile tests were conducted at room temperature and at strain rates from $2.5 \cdot 10^{-4}$ to $900 \mathrm{~s}^{-1}$. The low strain rate tests $\left(2.5 \cdot 10^{-4}\right.$ to $\left.10^{-1} \mathrm{~s}^{-1}\right)$ were performed with an Instron 8800 servohydraulic testing machine, and the high strain rate tests (600-900 $\mathrm{s}^{-1}$ ) with a Split Hopkinson Pressure Bar (SHPB). The tensile SHPB device comprises a high strength steel incident bar, an aluminum transmitted bar, and a striker tube. The striker was impacted with compressed air to a flange at the free end of the incident bar to generate a tensile loading pulse. These incident and transmitted stress pulses were measured using $5 \mathrm{~mm}$ strain gages bonded on the surfaces of the pressure bars. The strain gage signals were amplified with a Kyowa CDV 700A series signal conditioner and recorded with a $12 \mathrm{M}$ Sample Yokogawa digital oscilloscope. The data acquisition in the oscilloscope was triggered by the rising edge of the incident pulse. The influence of the longitudinal wave dispersion on the measured stress pulses was corrected with a numerical dispersion correction method adopted from the work of Gorham \& Wu [31]. The corrected pulses were then used to determine stress, strain, and strain rate of the sample during the test. More detailed description of the device can be found in references [30,32,33].

The full-field deformation and temperatures on the sample surface were synchronously obtained using a high-speed thermal camera and a stereo DIC system. At low strain rates, the deforming samples were illuminated by pulsed cold LED lights and monitored by Imager E-Lite 5MPix CCD cameras from LaVision with $100 \mathrm{~mm}$ lenses. In the high strain rate tests, Photron Fastcam SA-X2 high-speed cameras with $100 \mathrm{~mm}$ lenses were used together with Ultra-Bright cold LED modules for illumination. The surface temperatures of the samples in all tests were measured using a Telops Fast-IR $2 \mathrm{~K}$ Rapid IR camera with a $50 \mathrm{~mm}$ lens. The experimental setups used in the low strain rate and dynamic mechanical tests are shown in Fig. 2. The IR camera was positioned between the two optical cameras and in front of the patterned surface of the sample, or on the other side of the testing device and facing the non-patterned surface of the sample. The tests in which the IR camera was monitoring the patterned surface of the sample, a narrow stripe was left unpatterned to allow
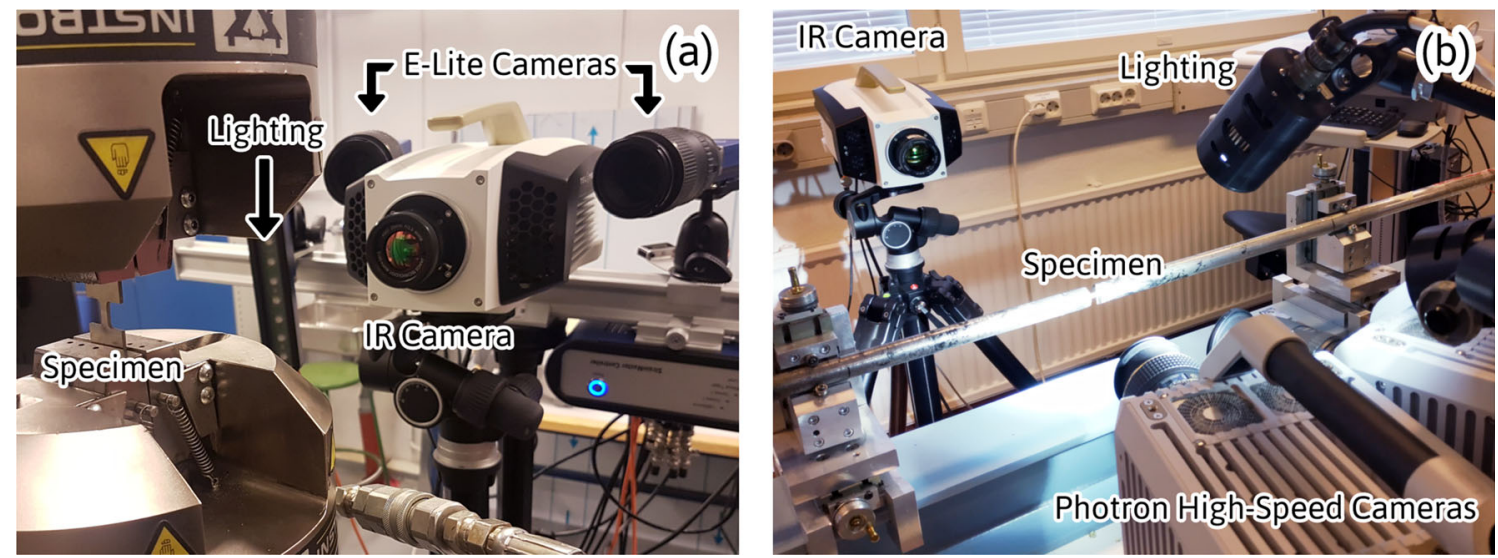

Fig. 2 Experimental setup for low strain rate tests (a), and high strain rate tests (b) 


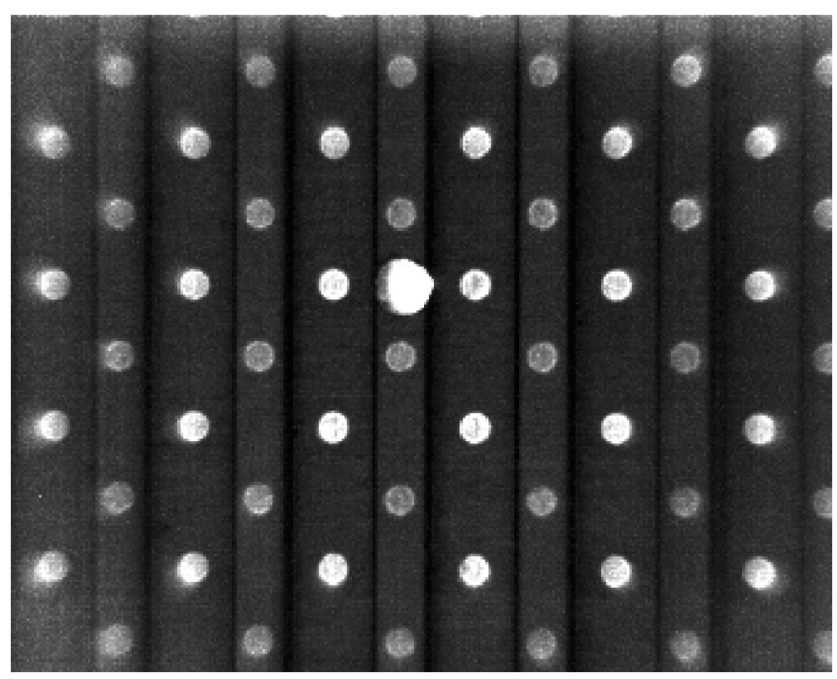

Fig. 3 Infrared image of the two-level double-sided 3D calibration plate used for translating both the optical cameras and the infrared camera to the same world coordinate system. Dimensions of the calibration plate are 58 by $58 \mathrm{~mm}$

temperature measurement of the clean metal surface. The strains and temperatures were considered equal on both sides of the specimens during testing as the specimens were thin.

Images of a two-level double-sided 3D calibration plate were taken for each test with both optical and infrared systems. The calibration plate was slightly heated (approximately $5-10{ }^{\circ} \mathrm{C}$ only) to improve the contrast in the IR images. Figure 3 shows an example image of the two-level doublesided 3D calibration plate acquired with the IR camera. The contrast between the calibration plate and the environment is due to its temperature being approximately $32^{\circ} \mathrm{C}$. It is important that the marks and fiducials or very distinguishable features on the calibration plate are clearly visible in the infrared camera images, and that the calibration plate should cover as much of the field of view of the image as possible. This ensures that the pinhole camera model can be precisely calibrated. The calibration plate can be effectively used at temperatures ranging from 0 to $40{ }^{\circ} \mathrm{C}$ according to the manufacturer
[34]. Considering that the calibration plate is made from an AlMnMg alloy, an increase of $10{ }^{\circ} \mathrm{C}$ would only amass to a total linear expansion of $0.024 \%$ [35], which would be present in both optical and infrared images. Based on these facts, the inaccuracies generated by the heating of the calibration plate were considered tolerable.

A Keysight 33500B waveform generator was used to synchronize the image acquisition on both optical and infrared systems. Table 2 shows the acquisition frequency and respective image resolution of the optical and infrared cameras for the tests at different strain rates. In the low strain rate tests, the TTL (Transistor-transistor logic) pulses synchronized the data acquisition by directly triggering the acquisition of each picture on both optical and infrared systems. However, the synchronization is not as simple on the setup for high strain rate testing, as the image acquisition of the Photron cameras cannot be triggered directly by a TTL pulse. The waveform generator was used as an external clock for the Photron cameras to continuously run the cameras at a preset external frequency and clock. This signal was continuously fed to an external controller, the StrainMaster Controller PTU, which then sent the clock signal to the cameras. The preset number of images was then obtained by triggering the image acquisition by a second TTL pulse. The Photron cameras required the TTL pulses to constantly clock the cameras, therefore, the same TTL pulse could not simply be sent to the IR camera as each pulse would trigger data acquisition. An analog gate or switch was built to block the TTL pulses from reaching the IR camera before the beginning of the test. The main trigger signal event of the test occurred when the tension stress pulse reached the incident bar strain gage. This activated the trigger on the digital oscilloscopes and the TTL pulse was sent to start image acquisition on the Photron cameras and to open the analog gate and thus initiating the image acquisition on the Telops camera. The image acquisition of both systems was therefore triggered as the stress pulse had reached the incident strain gage station. The schematic picture of the setup used to synchronize both optical and infrared systems in the high strain rate mechanical tests is presented in Fig. 4.

Table 2 Acquisition frequency and image resolution of the optical and infrared cameras for different strain rates

\begin{tabular}{llll}
\hline Strain rate $\left(\mathrm{s}^{-1}\right)$ & Acquisition frequency $(\mathrm{Hz})$ & Optical cameras resolution (pixel) & Infrared camera resolution (pixel) \\
\hline $2.5 \cdot 10^{-4} \& 3.3 \cdot 10^{-4}$ & 0.2 & $2456 \times 2058$ & $320 \times 256$ \\
$10^{-3}$ & 1 & $1800 \times 1800$ & \\
$10^{-2}$ & 10 & $1000 \times 1000$ & $64 \times 4$ \\
$10^{-1}$ & 12.5 & $512 \times 200$ & \\
$600-900$ & 90,000 & & \\
\hline
\end{tabular}




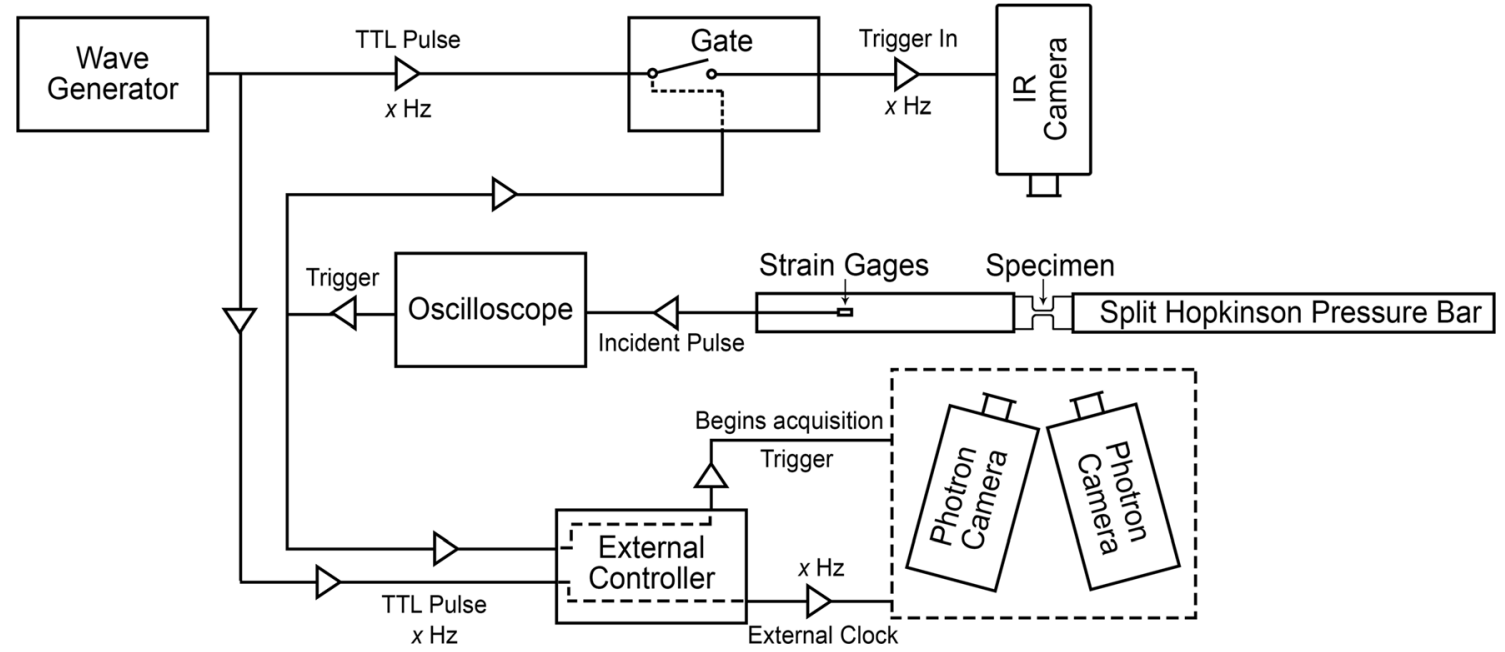

Fig. 4 Schematic picture of the image acquisition trigger circuit

\section{Data Processing}

The optical and infrared pictures of the calibration target were used to calibrate the intrinsic parameters of the pinhole camera model of each separate camera (physical scale, focal length, lens distortions, etc.) and the extrinsic parameters of the whole setup (angle and distance between cameras, distance from each camera to the sample, etc.). The intrinsic parameters were used to set an image scale and correct any image distortions in each camera, and the extrinsic parameters correction coefficients were used to translate the images to the same world coordinate system. The translation of raw images to the same (a)

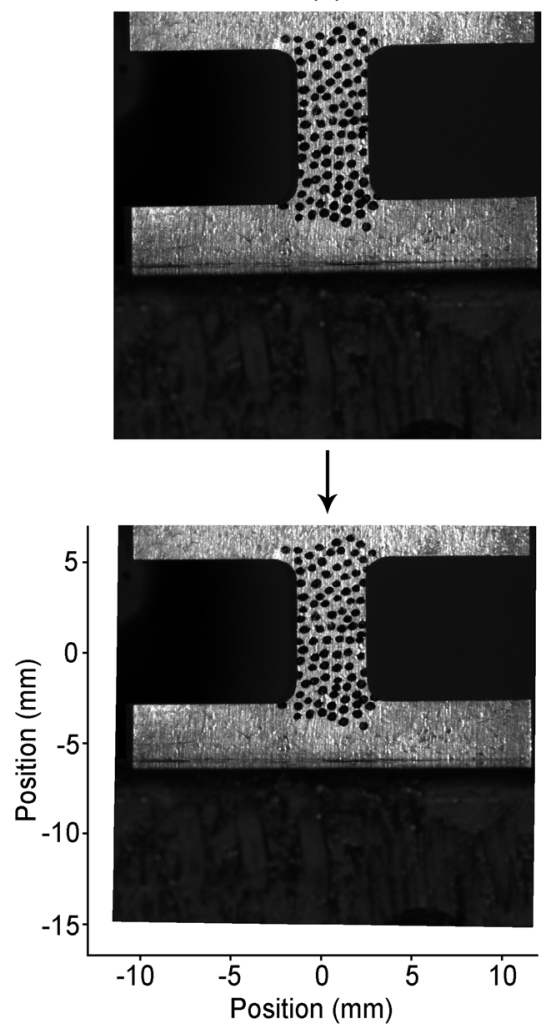

Optical Camera 1 (b)
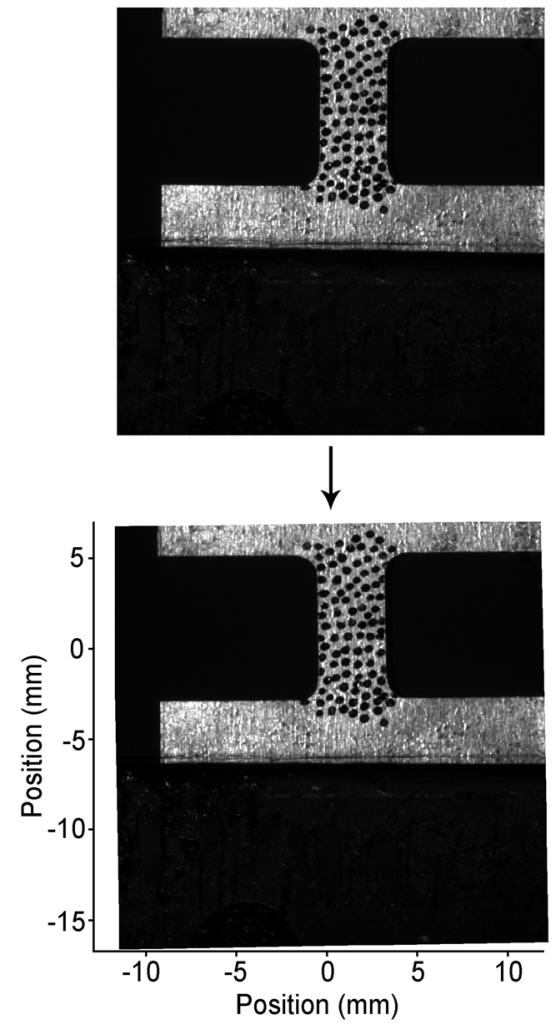

Optical Camera 2 (c)
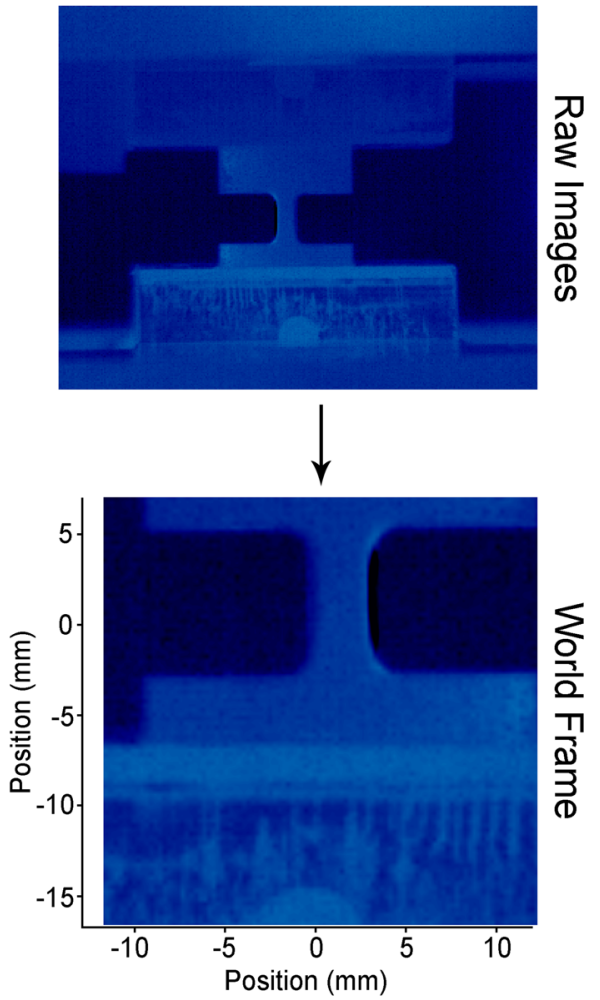

Infrared Camera

Fig. 5 Translation of the raw images to a world coordinate system using the pinhole camera model. Raw images are on the top row and the corrected images are on the bottom row. (a) and (b) are the optical images and (c) are the infrared images. The translation from the raw images to the world coordinate system can be seen in the slight tilting and resizing of the images from the upper to the lower images 
Table 3 Digital image correlation analysis parameters

\begin{tabular}{lll}
\hline & \multicolumn{2}{l}{ Strain rate $\left(\mathrm{s}^{-1}\right)$} \\
\cline { 2 - 3 } Parameter & $10^{-4}-10^{-1}$ & $600-900$ \\
\hline Subset size (pixel) & $45-69$ & $19-29$ \\
Step size (pixel) & $5-23$ & $6-9$ \\
VSG size (pixel) & $59-92$ & $25-38$ \\
Average stereo reconstruction error (pixel) & $0.01-0.09$ & $0.003-0.005$ \\
Strain noise floor (\%) & $0.01-0.07$ & $0.02-0.06$ \\
Standard deviation of the calibration model fit (pixel) & $0.02-0.8$ & $0.5-0.9$ \\
Image scale factor (pixel/mm) & $40-60$ & 27 \\
\hline
\end{tabular}

world coordinate system using the pinhole camera model is shown on Fig. 5.

The full-field displacement and strain vector fields were obtained with stereo DIC analysis. The correlation method used for the DIC was the sum-of-differentials. Although it is known that this correlation method leads to a sum of the deviance throughout the analysis, it was necessary to keep them for maintaining decent correlation throughout the necking and for the samples with a large change in surface roughness. The matching criteria was the Zero-Normalized Sum of Squared Differences (ZNSSD), the subset shape function was affine, the interpolant was a 6th order spline function, and the subset weighting function was Gaussian. The details of the calculation parameters used for the DIC for the tests conducted at different strain rates are shown in Table 3. The full-field strain data obtained from DIC was represented in the Lagrangian or material frame of reference. When the sample deforms and moves during the testing, the coordinate system of the strain field moves with the specimen instead of the pixel coordinates of the camera. However, the temperature maps are represented in an Eulerian or pixel reference frame, in which the spatial coordinates of the sample change with time. Therefore, to ensure the correspondence between the strain and thermal data, the displacement vector field obtained in the DIC analysis was used to remove the shift caused by the displacement of the sample during testing from the thermal images, and represent the temperature in the same Lagrangian frame of reference as the strain data. Figure 6 shows an example of this translation of the temperature maps from an Eulerian to a Lagrangian frame of reference.

\section{Temperature Calibration}

The Telops IR camera assumes that the observed target is a black body and the surface has an emissivity of 1.0 [26]. It, therefore, underestimates the true surface temperature of the (a)

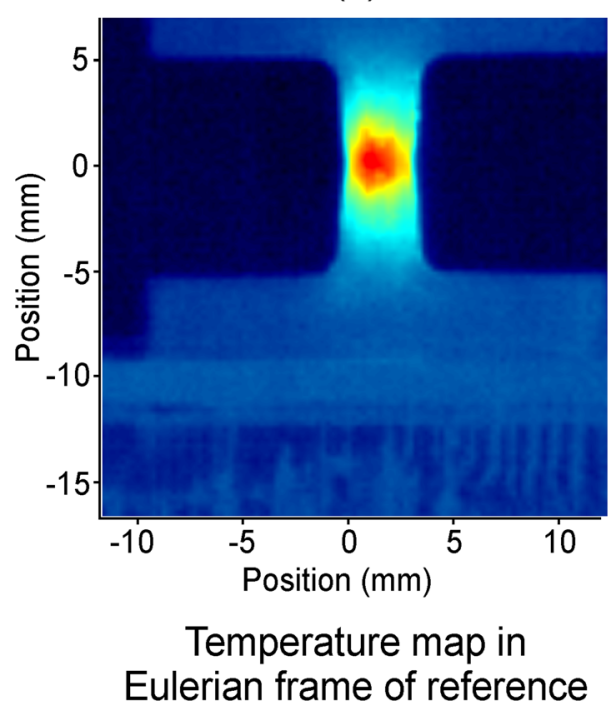

(b)
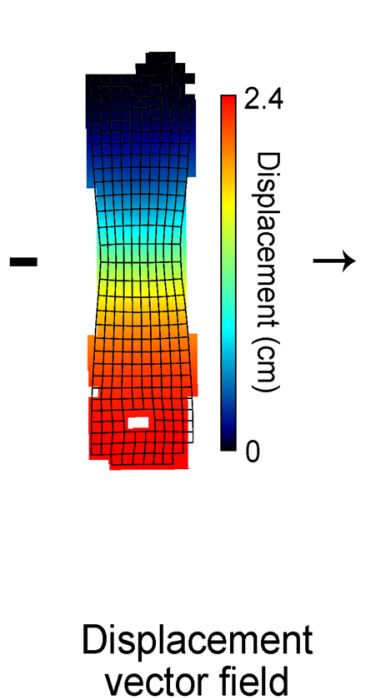

(c)

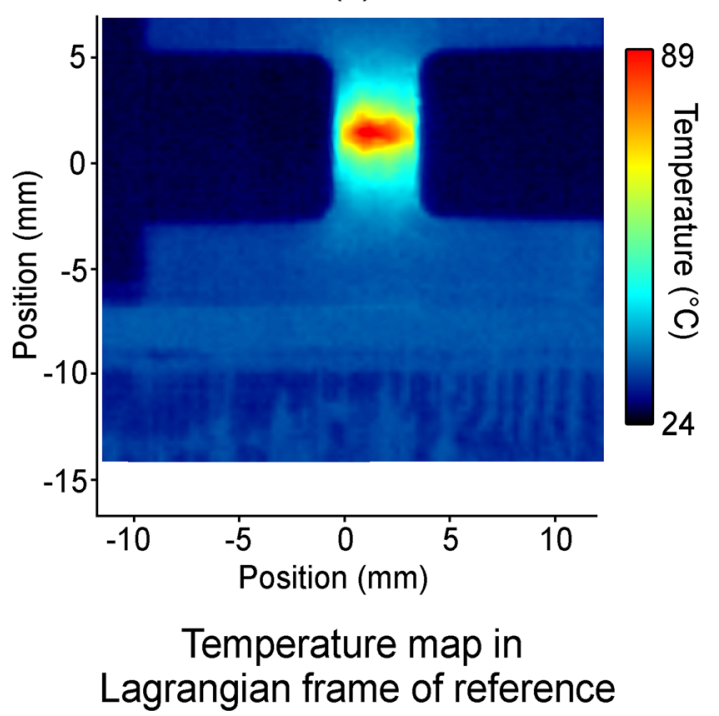

Fig. 6 Translation of a temperature map from a Eulerian to a Lagrangian frame of reference by removing the DIC displacement vector field from the infrared images. (a) Temperature map in the Eulerian frame of reference, (b) DIC's displacement vector field, and (c) temperature map in the Lagrangian frame of reference 
sample as the emissivity of the investigated materials is certainly lower than 1.0. A calibration of the radiometric temperatures to true surface temperatures was carried out by heating a specimen on a hot plate while simultaneously recording the temperature of the specimen by both the IR camera and spot welded thermocouples. The calibration measurements were carried out using the same experimental and imaging parameters as in the tension tests. Figure 7 shows the experimental setup used for the infrared measurements calibration and an example calibration curve for the AISI316 steel obtained with an integration time of $5 \mu$ s.

\section{Evaluation of the Synchronization Errors}

Both the optical and the infrared high-speed cameras have different reaction times to the triggering TTL pulses. Further uncertainty is caused by the electronic circuits and components through which the TTL pulses pass before reaching the cameras. The desynchronization error was defined as the difference between the image acquisition of the high-speed optical and infrared cameras. Coaxial cables of the same length connected the wave generator to both the optical cameras and the infrared camera, therefore they do not add up to the desynchronization of the pulses. The measured delay added to the pulse by traversing the StrainMaster Controller PTU was of $918 \pm 2$ ns. A pulse of at least $200 \mathrm{~ns}$ is required to externally clock the Photron cameras [36], which further adds to the delay as the camera needs to wait this much time before it realizes that it has received a clocking signal. Furthermore, an error of $15.4 \mathrm{~ns}$ is further added by having the Photron high- speed cameras in their externally clocked mode. The maximum delay between the generation of the TTL pulse and the true triggering of the Photron cameras is approximately $1133 \mathrm{~ns}$. As for the infrared system, the minimum rise time for the TTL pulse to trigger the Fast-IR $2 \mathrm{~K}$ is of $50 \mathrm{~ns}$ and the maximum random jitter due to the internal clocking of the Fast-IR $2 \mathrm{~K}$ is approximately 300 ns. There was no measurable delay added by the analog gate device. The maximum delay added to the TTL pulse to trigger the IR camera was estimated as $350 \mathrm{~ns}$. The maximum desynchronization error would occur in the case when the delay is maximum for the optical cameras and minimum for the infrared camera. In this situation, the random jitter of the infrared camera would be $0 \mathrm{~ns}$ and the infrared camera delay would of $50 \mathrm{~ns}$. The maximum desynchronization error would then be of 1083 ns. Nevertheless, the difference between the output signals from both optical and infrared systems indicated that the average occurring delay between the acquisition was close to $200 \mathrm{~ns}$.

\section{Mechanical Characterization}

Figure 8 shows the stress-strain plots of the investigated materials at different strain rates. The AISI301 is a metastable austenitic stainless steel with a low stacking fault energy. At the lower strain rates, its mechanical strength and strain hardening rates are enhanced by a strain induced martensitic transformation. This phase transformation is also evidenced by the sinusoidal shape of the stress strain curve [37]. The highest tensile strength of roughly $950 \mathrm{MPa}$ was observed on the AISI301 at a strain rates (a)

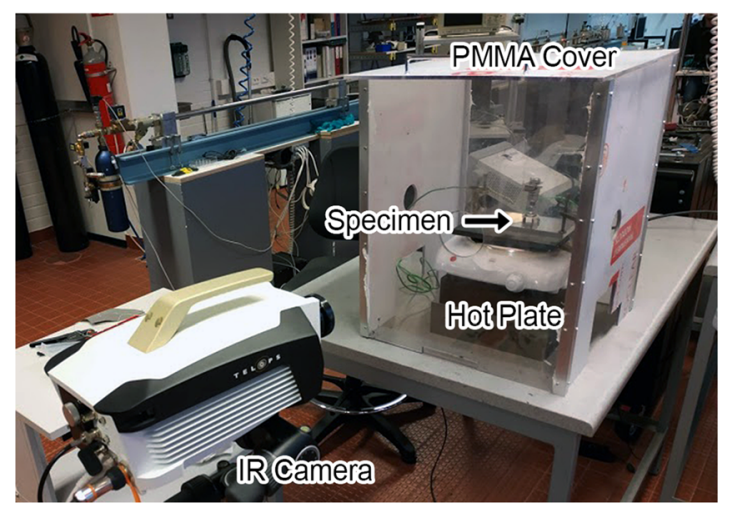

(b)

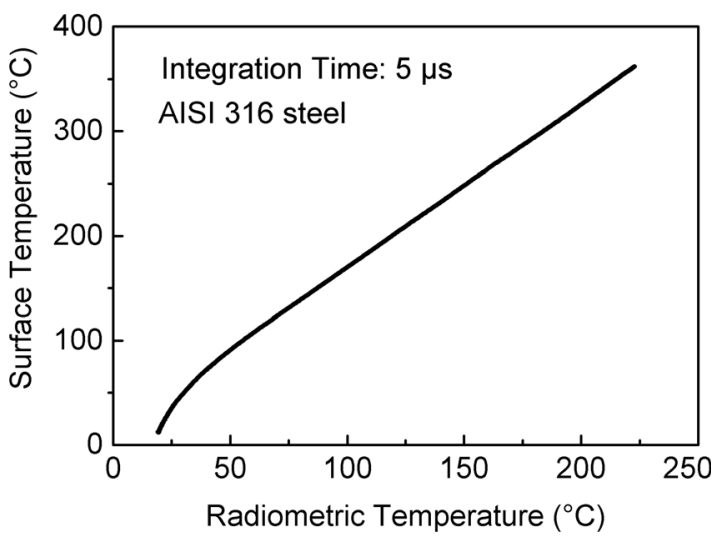

Fig. 7 (a) Temperature calibration setup comprising the infrared camera, a hot plate, a specimen with thermocouples and the plexiglass cover and (b) surface temperature as a function of radiometric temperature of an AISI3 16 steel with a $5 \mu$ s integration time 
of $2.5 \cdot 10^{-4} \mathrm{~s}^{-1}$. The most ductile material was the AISI316, reaching total elongations of approximately $70 \%$ at the lower strain rates of $2.5 \cdot 10^{-4}$ and $10^{-2} \mathrm{~s}^{-1}$. A low strain rate sensitivity was observed in the low alloy TRIP in the low strain rate tests $\left(3.3 \cdot 10^{-4}-10^{-1} \mathrm{~s}^{-1}\right)$. At the strain rate of $900 \mathrm{~s}^{-1}$ the mechanical strength increased considerably. The TWIP has the lowest mechanical strength among the investigated materials, but an intermediate ductility of approximately $50 \%$ engineering strain. Mechanical strength was considerably higher in the test at $850 \mathrm{~s}^{-1}$ due to the extensive twin formation, which is expected at high strain rates [28]. The AISI316 and TRIP steels have positive strain rate sensitivities at least in most of the test, as the flow stresses increased with an increase in strain rate. The AISI301 has negative strain rate sensitivity at large plastic strains. This is caused by the suppression of the strain induced phase transformation at higher strain rates [37]. The TWIP also has negative strain rate sensitivity between engineering strain of 0 and $30 \%$ at the strain rate of $850 \mathrm{~s}^{-1}$, which could be related to the negative strain rate sensitivity of mechanical twinning [28].

\section{Results and Discussion}

The full-field localized strains and temperatures were plotted as a function of global engineering strain and position along the gauge length. The tests were fundamentally isothermal at the strain rate of $2.5 \cdot 10^{-4}-10^{-2} \mathrm{~s}^{-1}$ and adiabatic at $10^{-1}-900 \mathrm{~s}^{-1}$. Figure 9 shows an example 3D waterfall plot of the temperature rise and localized strain as a function of the global engineering strain and the position for the AISI316 deformed at the strain rate of $10^{-1} \mathrm{~s}^{-1}$. At the strain rate of $3 \cdot 10^{-4} \mathrm{~s}^{-1}$, the temperature rise was negligible throughout the sample gauge length for all investigated materials. At the strain rate of $10^{-2} \mathrm{~s}^{-1}$, the AISI301 steel was the only material that heated up considerably, up to $30{ }^{\circ} \mathrm{C}$, during necking. The maximum temperature increases for the AISI316, TRIP, and TWIP at the strain rate of $10^{-2} \mathrm{~s}^{-1}$ were $15{ }^{\circ} \mathrm{C}, 18{ }^{\circ} \mathrm{C}$ and $10^{\circ} \mathrm{C}$. The localized strain profiles were markedly similar for each material at the strain rates of $3 \cdot 10^{-4} \mathrm{~s}^{-1}$ and $10^{-2} \mathrm{~s}^{-1}$. For the sake of brevity, the localized strain and temperature waterfall plots for the strain rates of $3 \cdot 10^{-4} \mathrm{~s}^{-1}$ and $10^{-2} \mathrm{~s}^{-1}$ are shown in Appendix Figures 12 and 13. The ductility of the AISI301 and AISI3 36 was the highest and their maximum localized strains in the necking region were approximately $160 \%$ and $225 \%$. The maximum localized strain in the necking region of the less ductile TRIP and TWIP steels were of approximately $75 \%$ and $125 \%$.
Figures 10 and 11 show the waterfall plots of temperature and localized strain as a function of global engineering strain and position along the gauge length of the sample for the tests carried out at the strain rates of $0.1 \mathrm{~s}^{-1}$ and 600 $900 \mathrm{~s}^{-1}$. The highest temperature increase at the strain rate of $0.1 \mathrm{~s}^{-1}$ was observed for the AISI301. Temperature increased considerably throughout the whole gauge length of the sample during uniform deformation, and was moderately localized after the onset of necking. This large increase in temperature during uniform deformation is promoted by the exothermal strain induced martensitic transformation. The temperature increase during uniform deformation was much lower on the AISI316. This lower increase in temperature during uniform deformation is expected as the AISI316 steel is more stable austenitic steel and its deformation is based on dislocation glide only. Nevertheless, the temperature increase of the AISI316 steel was very localized and especially the temperature increase in the necking region was high. This localized increase in temperature in the neck region is explained mainly due to strain localization, but the occurrence of strain induced martensite formation during necking has also contributed for this temperature increase. The presence of the martensite on the neck region due to localized deformation was confirmed by X-ray diffraction and magnetic balance measurements [37].

The temperature increase of the low-alloy TRIP steel tested at $10^{-1} \mathrm{~s}^{-1}$ was only moderate, despite its deformation being assisted by a strain induced martensitic transformation. However, compared to the AISI301, the low-alloy TRIP steel only has maximum of $\sim 12 \%$ of austenite in its microstructure that could possibly transform to martensite and contribute to the additional heating [38]. The temperature rise of the TWIP steel at $10^{-1} \mathrm{~s}^{-1}$ was also rather low, with a maximum temperature increase of $50^{\circ} \mathrm{C}$, despite the fact that it reached localized strains of $\sim 100 \%$ during necking.

All the investigated materials were deformed to approximately $40 \%$ maximum deformation in the high rate experiments. Necking and failure were only observed in the TRIP, as shown in Fig. 11(e), (f). The other tested materials were more ductile, and the specimens did not break with the first tensile loading pulse. It is clear in Fig. 11(e), (f) that necking occurred in the same frame in both the optical cameras and the infrared camera, which further corroborates the data acquisition synchronization. It is also noteworthy that the fracture was observed at the same time and at the same position in the world frame, verifying the successful translation of the strain and temperature data to the world coordinate system and Lagrangian frame of reference. Among all investigated 

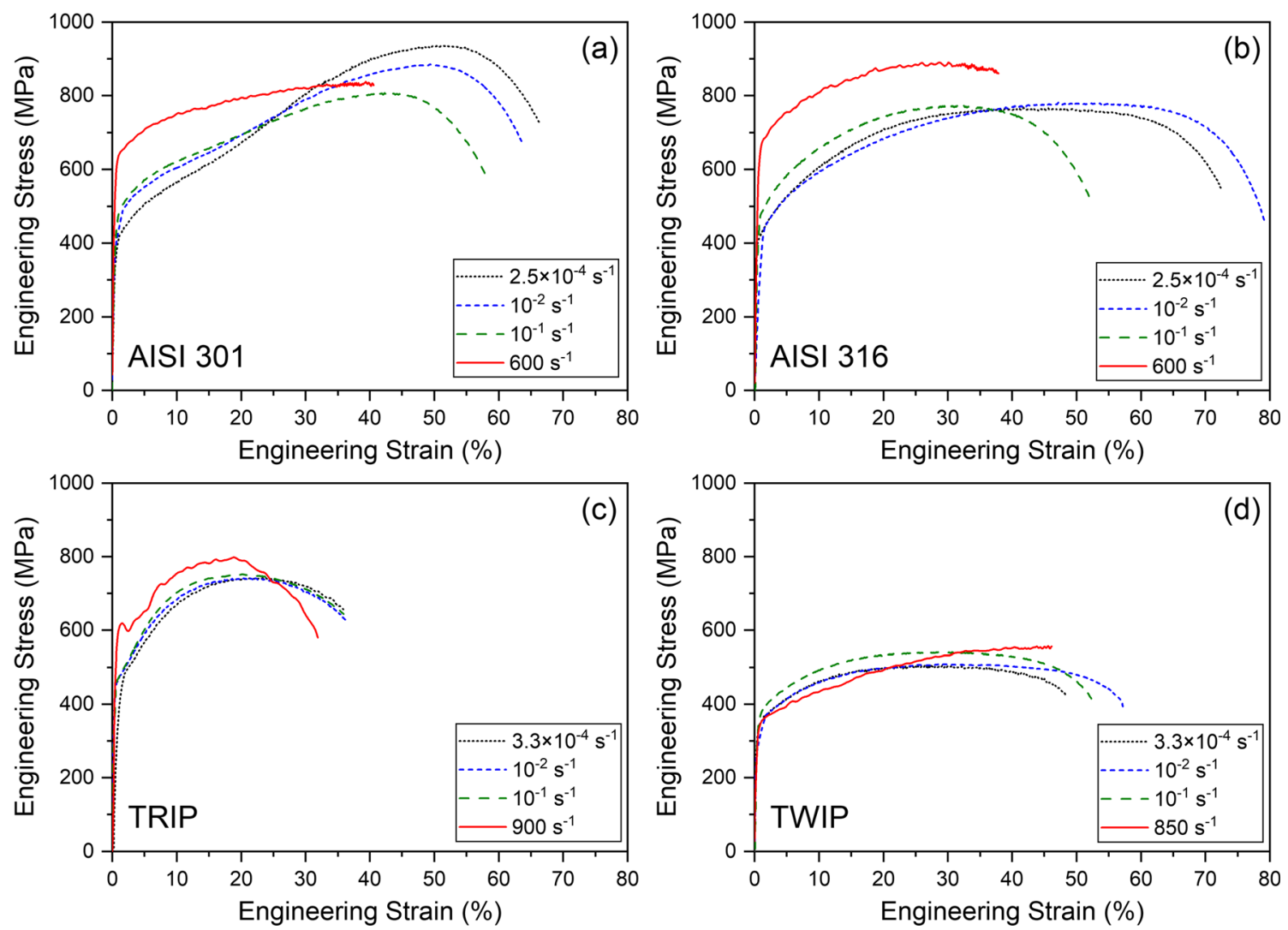

Fig. 8 Stress-strain curves for the (a) AISI301, (b) AISI316, (c) TRIP, and (d) TWIP steels

materials and strain rates, the temperature rise during necking was the highest for the TRIP steel tested at a strain rate of $900 \mathrm{~s}^{-1}$, reaching approximately $300{ }^{\circ} \mathrm{C}$. The strain localization profile of necking in the TRIP steel was considerably similar for all strain rates, having some- what lower localized strains distributed along a longer length, which is visualized as a low and wide peak in the waterfall plots. The necking in the low-alloy TRIP steel is, more diffuse rather than a sharp localization. This feature could be related to the delay of necking
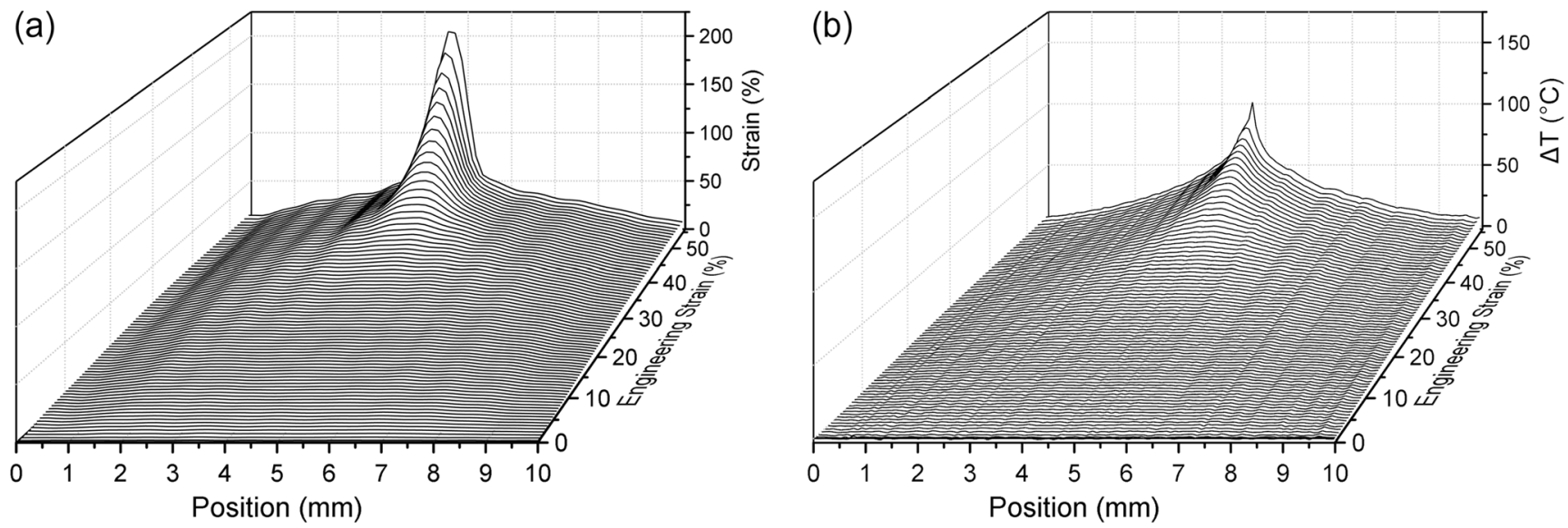

Fig. 9 3D Waterfall plots of localized strain and temperature rise of the AISI316 deformed at a strain rate of $0.1 \mathrm{~s}^{-1}$ 

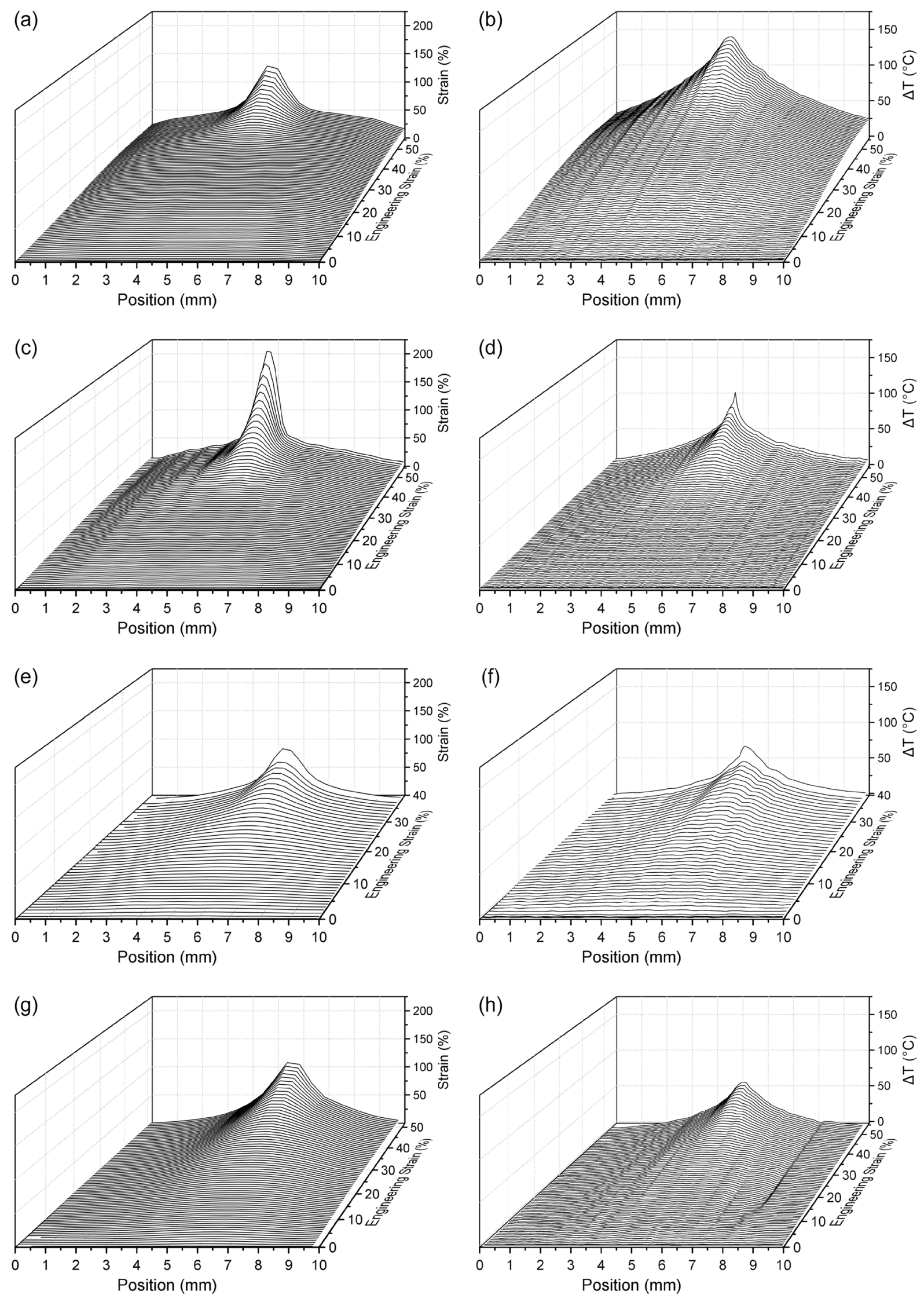

Fig. 10 3D Waterfall plots of localized strain $(\mathbf{a}, \mathbf{c}, \mathbf{e}, \mathbf{g})$ and temperature rise $(\mathbf{b}, \mathbf{d}, \mathbf{f}, \mathbf{h})$ for the (a, b) AISI301, (c, d) AISI316, (e, f) TRIP, and (g, h) TWIP steels deformed at a strain rate of $0.1 \mathrm{~s}^{-1}$ 

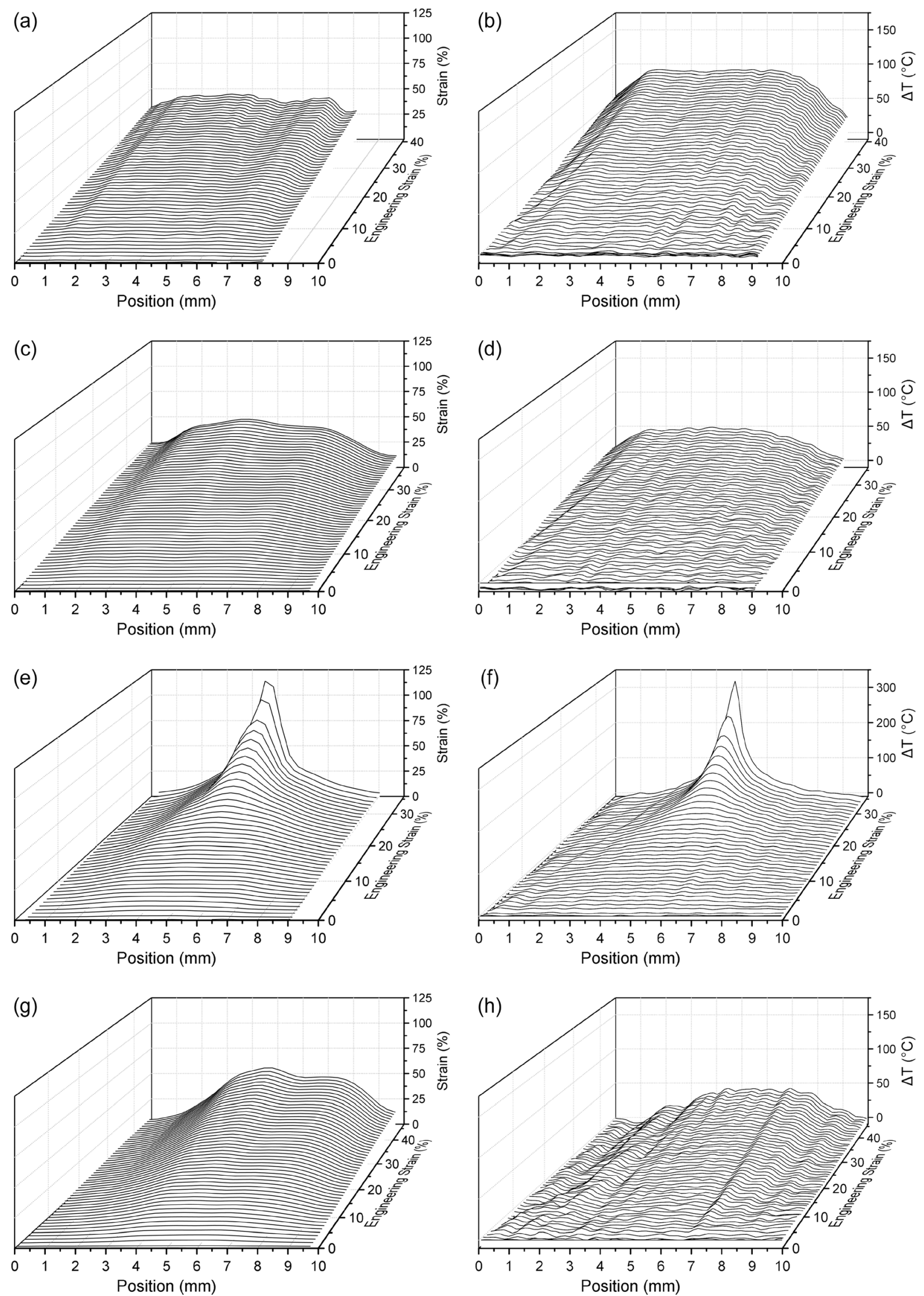

Fig. 11 3D Waterfall plots of localized strain $(\mathbf{a}, \mathbf{c}, \mathbf{e}, \mathbf{g})$ and temperature rise $(\mathbf{b}, \mathbf{d}, \mathbf{f}, \mathbf{h})$ for the (a, b) AISI301, (c, d) AISI316, (e, f) TRIP, and (g, h) TWIP steels deformed at a strain rates from 600 to $900 \mathrm{~s}^{-1}$ 
caused by the localized martensite formation after every onset of microscopic necking. According to Huang [39], the dynamic formation of martensite during necking can locally enhance mechanical strength and stabilize flow. On the topic of TRIP steels, Krauss [40] has stated that the strain-induced transformation of small amounts of retained austenite can locally increase strain hardening rate, postpone necking instability and promote ductility. The formation of martensite can locally strengthen the material, compensating for the reduction of the cross sectional area and causing microscopic necking to occur in the next weakest region of the material. At some point the increase in strain hardening rate provided by the straininduced transformation is not sufficient to defer necking, which leads the TRIP steel to fail without high localized strain in the necking region, resulting in the lower localized strains and flatter profile observed in the waterfall plots. Soares et al. [41] have reported a similar flat surface fracture profile due to strain-induced martensite forming during necking and leading to local strengthening in a 304 steel.

The deformation was uniform until $40 \%$ strain for the AISI301, AISI316, and TWIP. Temperature and localized strains increased uniformly throughout the gauge length of the AISI301, AISI316, and TWIP steel samples that did not neck during testing in the high strain rate experiments. The AISI301, AISI316, and TWIP steels had temperature increases of $90^{\circ} \mathrm{C}, 50^{\circ} \mathrm{C}$, and $40^{\circ} \mathrm{C}$, respectively, during uniform deformation at high strain rate. The temperature increase for comparable strain was considerably higher at strain rates of $600-900 \mathrm{~s}^{-1}$ than those observed at $10^{-1} \mathrm{~s}^{-1}$, evidence of the more pronounced adiabatic heating in dynamic tests.

The strain localization during necking at the strain rates of $3 \cdot 10^{-4}, 10^{-2}$ (Appendix Figs. 12 and 13) and $10^{-1} \mathrm{~s}^{-1}$ (Fig. 10) was similar for AISI301 and AISI316, and did not seem to be greatly affected by the temperature rise. However, the neck formation of the TRIP steel at the strain rate of $900 \mathrm{~s}^{-1}$ (Fig. 11) was significantly different from that observed at lower strain rates, which could be related to the dynamic nature of the test or the changes in material behavior due to the $300{ }^{\circ} \mathrm{C}$ temperature increase.

\section{Conclusion}

The method described in this work makes it possible to accurately study the thermomechanical response of a material at low and high strain rates using synchronized full-field stereo DIC and IRT. This method was used to investigate the thermomechanical tension behavior of four different advanced steels at strain rates of $2.5 \cdot 10^{-4}$ to $900 \mathrm{~s}^{-1}$. The use of an external function generator together with an analog gate allowed data acquisition among all cameras to be synchronized. The use of stereo DIC and a spatial calibration made it possible to represent both strain and temperature data in the same world frame, and to evaluate and correct any out-ofplane motion that occurred during testing. The displacement vector fields from DIC were applied to the IR data to have both strain and temperature maps represented in a Lagrangian frame of reference. By combining the global engineering strain, localized strain, and temperature along the gauge length, it was possible to visualize the thermomechanical behavior of the investigated materials using $3 \mathrm{D}$ waterfall plots. These plots describe the evolution of local strains and local temperatures during the experiment and can be useful to investigate the thermomechanical behavior of materials and validating complex material models. No temperature rise was observed in the tests at the lowest strain rate $\left(10^{-4} \mathrm{~s}^{-1}\right)$, a small temperature increase was observed during necking at the strain rate of $10^{-2} \mathrm{~s}^{-1}$, whereas temperature rose uniformly with plastic strain at higher strain rates $\left(10^{-1}-900 \mathrm{~s}^{-1}\right)$ and was localized on the necking region. The novelty of this work is in the accurate synchronization of DIC and IRT data acquisition in the high-speed tests and in the usage of stereo DIC to properly match the strain and temperature data in the same world coordinate system. The highest temperature increase during uniform deformation was observed for the AISI301 steel, which occurred due to the exothermal nature of the strain induced martensitic phase transformation which occurs during deformation. The temperature increase during necking in the TWIP steel was considerably lower than that observed in the other investigated materials. The highest temperature increase during necking was of approximately $300{ }^{\circ} \mathrm{C}$ which was observed for the TRIP steel tested at $900 \mathrm{~s}^{-1}$. The strain localization or necking of the TRIP steel was more diffuse and expanded to a larger length while the maximum strains were lower, whereas the temperature rise profile was higher in the high strain rate test $\left(900 \mathrm{~s}^{-1}\right)$ than in the lower strain rates $\left(10^{-4}-10^{-1} \mathrm{~s}^{-1}\right)$. The fracture of the TRIP steel sample was observed in the same image in all the three high-speed systems, which was considered as further validation of the successful data acquisition synchronization in the proposed method.

\section{Compliance with Ethical Standards}

On behalf of all authors, the corresponding author states that there is no conflict of interest. The authors declare no ethical conflicts, competing financial and/or non-financial interests. 


\section{APPENDIX}
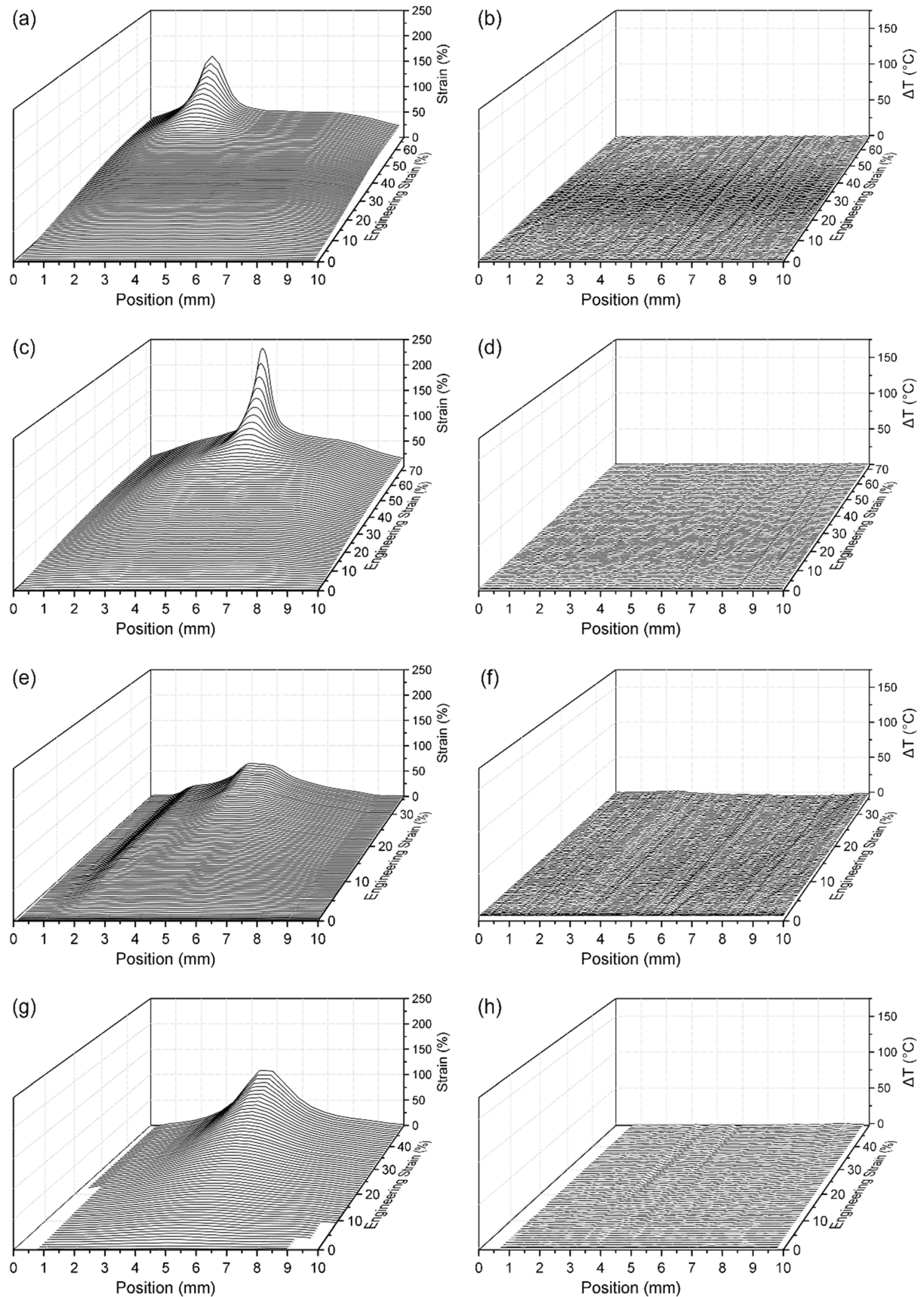

Fig. 12 3D Waterfall plots of localized strain (a, c, e, g) and temperature (b, $d, f, h)$ of the (a, b) AISI301, (c, d) AISI316, (e, f) TRIP, and (g, h) TWIP steels deformed at a strain rate of approximately $10^{-4} \mathrm{~s}^{-1}$ 

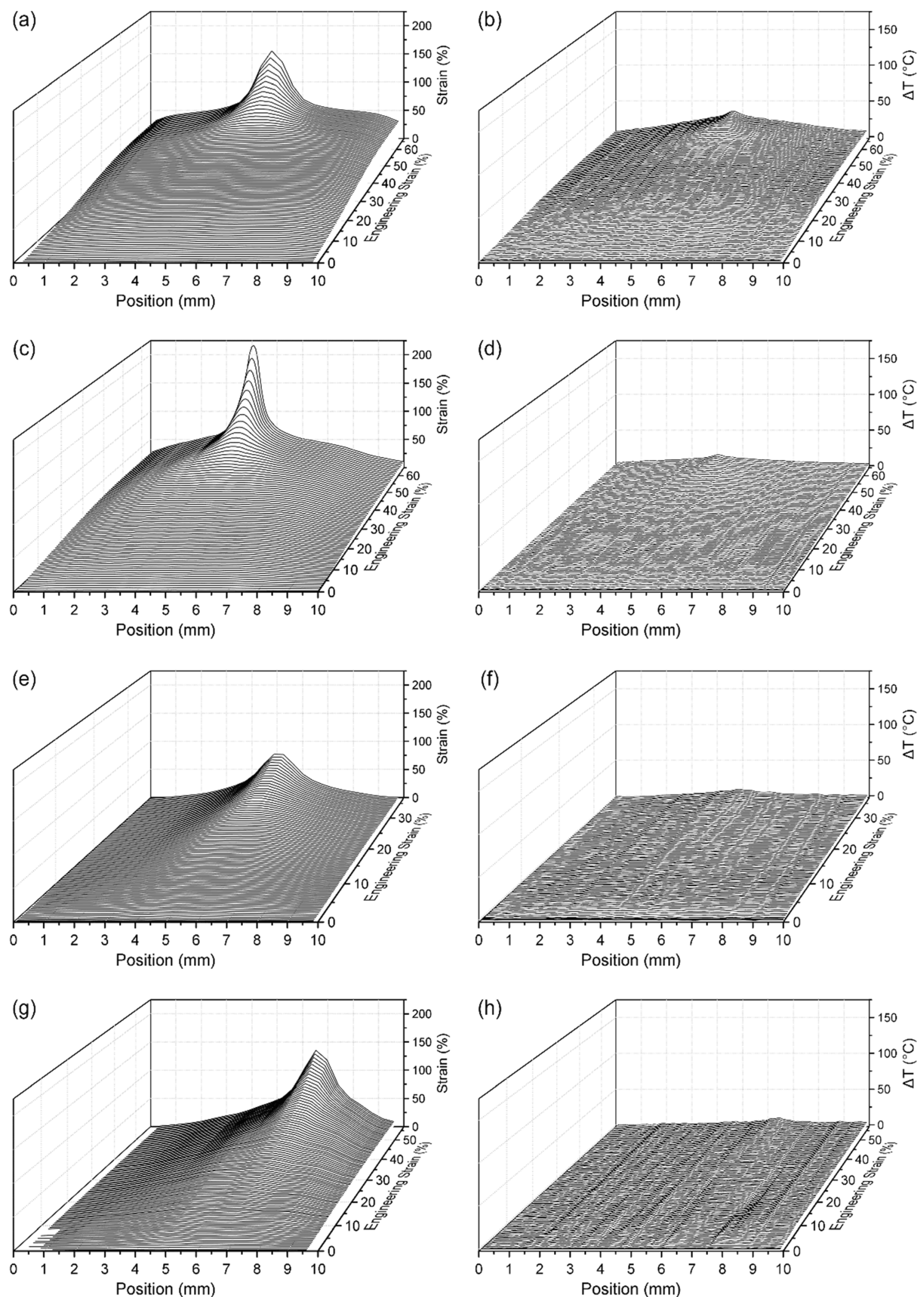

Fig. 13 3D Waterfall plots of localized strain (a, c, e, g) and temperature (b, d, f, h) of the (a, b) AISI301, (c, d) AISI316, (e, f) TRIP, and (g, h) TWIP steels deformed at a strain rate of approximately $10^{-2} \mathrm{~s}^{-1}$ 
Open Access This article is licensed under a Creative Commons Attribution 4.0 International License, which permits use, sharing, adaptation, distribution and reproduction in any medium or format, as long as you give appropriate credit to the original author(s) and the source, provide a link to the Creative Commons licence, and indicate if changes were made. The images or other third party material in this article are included in the article's Creative Commons licence, unless indicated otherwise in a credit line to the material. If material is not included in the article's Creative Commons licence and your intended use is not permitted by statutory regulation or exceeds the permitted use, you will need to obtain permission directly from the copyright holder. To view a copy of this licence, visit http://creativecommons.org/licenses/by/4.0/.

\section{References}

1. Davis JR (2004) Tensile testing, 2nd ed. ASM International, Materials Park, OH, pp 1-283

2. Mirone $\mathrm{G}$ et al (2013) Mech Mater 58:84-96

3. Louche H, Chrysochoos A (2001) Thermal and dissipative effects accompanying Lüders band propagation. Mater Sci Eng A 307(12): $15-22$

4. Xiang GF, Zhanc QC, Liu HW, Wu XP, Ju XY (2007) Timeresolved deformation measurements of the Portevin-Le Chatelier bands. Scr Mater 56(8):721-724

5. Marchand A, Duffy J (1988) An experimental study of the formation process of adiabatic shear bands in a structural steel. J Mech Phys Solids 36(3):251-283

6. Gilat A, Schmidt TE, Walker AL (2009) Full field strain measurement in compression and tensile split hopkinson bar experiments. Exp Mech 49:291-302

7. Koerber H, Xavier J, Camanho P (2010) High strain rate characterisation of unidirectional carbon-epoxy IM7-8552 in transverse compression and in-plane shear using digital image correlation. Mech Mater 42:1004-1019

8. Peirs J, Verleysen P, Van Paepegem W, Degrieck J (2011) Determining the stress-strain behaviour at large strains from high strain rate tensile and shear experiments. Int J Impact Eng 38(5): 406-415

9. Zhang QB, Zhao J (2013) Determination of mechanical properties and full-field strain measurements. Int J Rock Mech Min 60:423439

10. Moilanen CS, Saarenrinne P, Engberg BA, Björkqvist T (2015) Image-based stress and strain measurement of wood in the splitHopkinson pressure bar. Meas Sci Technol 26(8):1-12

11. Johsen J, Grytten F, Hopperstad OS, Clausen AH (2016) Experimental set-up for determination of the large-strain tensile behaviour of polymers at low temperatures. Polym Test 53:305313

12. Verleysen P, Peirs J (2017) Quasi-static and high strain rate fracture behaviour of Ti6A14V. Int J Impact Eng 108:370-388

13. Neumayer J, Kuhn P, Koerber H, Hinterhölzl R (2016) Experimental determination of the tensile and shear behaviour of adhesives under impact loading. J Adhes 92(7-9):503-516

14. Fuller KNG, Fox PG, Field JE (1975) The temperature rise at the tip of fast-moving cracks in glassy polymers. Proc R Soc A 341(1627): $537-557$

15. Rittel D (1998) Transient temperature measurement using embedded thermocouples. Exp Mech 38(2):73-78
16. Rittel D (1998) Experimental investigation of transient thermoelastic effects in dynamic fracture. Int J Solids Struct 35(22):2959-2973

17. Rittel D (1999) On the conversion of plastic work to heat during high strain rate deformation of glassy polymers. Mech Mater 31(2): 131-139

18. Zhou M, Rosakis AJ, Ravichandran G (1996) Dynamically propagating shear bands in impact-loaded prenotched plates - II. Numerical simulations. J Mech Phys Solids 44(6):1007-1021

19. Zehnder A, Rosakis A (1991) On the temperature distribution at the vicinity of dynamically propagating cracks in 4340 steel. J Mech Phys Solids 39(3):385-415

20. Zhang LH, Rittel D, Osovski S (2018) Thermo-mechanical characterization and dynamic failure of near $\alpha$ and near $\beta$ titanium alloys. Mater Sci Eng A 729:94-101

21. Noble J, Harding J (1994) Temperature measurement in the tensile Hopkinson bar test. Meas Sci Technol 5(9):1163-1171

22. Gilat A, Kuokkala V-T, Seidt JD, Smith JL (2017) Full-field measurement of strain and temperature in quasi-static and dynamic tensile tests on stainless steel 316L. Procedia Eng 207:1994-1999

23. Seidt JD, Kuokkala V-T, Smith JL, Gilat A (2017) Synchronous full-field strain and temperature measurement in tensile tests at low, intermediate and high strain rates. Exp Mech 57:219-229

24. Johnston JP, Pereira JM, Ruggeri CR, Roberts GD (2018) Highspeed infrared thermal imaging during ballistic impact of triaxially braided composites. J Compos Mater 52(25):3549-3562

25. International Digital Image Correlation Society, Jones EMC, Iadicola MA (Eds) (2018) A Good Practices Guide for Digital Image Correlation. https://doi.org/10.32720/idics/gpg.ed1

26. Smith JL, Seidt JD, Gilat A (2019) Full-Field determination of the taylor-quinney coefficient in tension tests of Ti-6Al-4V at strain rates up to 7000-1. 3:133-139

27. Chrysochoos A, Huon V, Jourdan F, Muracciote J-M, Peyroux R, Wattrisse B (2010) Use of full-field digital image correlation and infrared thermography measurements for the thermomechanical analysis of material behaviour. Strain 46:117-130

28. Curtze S, Kuokkala V-T (2010) Dependence of tensile deformation behavior of TWIP steels on stacking fault energy, temperature and strain rate. Acta Mater 58(15):5129-5141

29. Hokka M, Curtze S, Kuokkala V-T, Peura P (2008) Dynamic response of high-manganese TWIP steels. In: Proceedings of the 2008 SEM XI international congress and exposition on experimental and applied mechanics, Orlando

30. Hokka M (2008) Effects of strain rate and temperature on the mechanical behavior of advanced high strength steels, Tampere: Doctoral Thesis, Tampere University of Technology

31. Gorham DA, Wu XJ (1997) An empirical method of dispersion correction in the compressive Hopkinson Bar Test. Le J Phys IV 07(8):223-228

32. Isakov M, Östman K, Kuokkala V-T (2014) Metastable austenitic steels and strain rate history dependence. In: Challenges in mechanics of time-dependent materials and processes in conventional and multifunctional materials, Volume 2, Springer, 2014, pp 99-108

33. Curtrze S (2009) Characterization of the dynamic behavior and microstructure evolution of high strength sheet steels. Tampere: Doctoral Thesis, Tampere University of Technology

34. LaVision (2019) 3D Calibration Plate for FlowMaster and StrainMaster systems. Retrieved from https://www.lavision.de/en/ download.php?id=3678

35. Cverna F (2002) ASM Ready Reference: Thermal properties of metals. ASM International, Russell 
36. PHOTRON (2013) FAST CAM SA-X2 FASTCAM SA-X2 RV Hardware Manual Revision 1.00 USEU, Tokyo: PHOTRON LIMITED

37. Vázquez-Fernández N, Nyyssönen T, Isakov MHM, Kuokkala V-T (2019) Uncoupling the effects of strain rate and adiabatic heating on strain induced martensitic phase transformations in a metastable austenitic steel. Acta Mater 176:134-144

38. Curtze S, Kuokkala V-THM, Peura P (2009) Deformation behavior of TRIP and DP steels in tension at different temperatures over a wide range of strain rates. Mater Sci Eng A 507(1-2):124-131

39. Huang G, Matlock D, Krauss G (1989) Martensite formation, strain rate sensitivity, and deformation behavior of type 304 stainless steel sheet. Metall Trans A 20A:1239-1246
40. Krauss G (2015) TRIP steels: microstructure and properties. In: Steels : processing, structure, and performance. ASM International pp. 217, 259, 265-266

41. Soares GC, Rogrigues MCM, Santos LA (2017) Influence of temperature on mechanical properties, fracture morphology and strain hardening behavior of a 304 stainless steel. Mater Res 20(2):141151

Publisher's Note Springer Nature remains neutral with regard to jurisdictional claims in published maps and institutional affiliations. 